- Reduced curriculum time requires that the complete denture course be shortened.

- The merits of a replacement complete denture technique are explored.

- The literature does not support the view that replacement denture techniques are any more than an alternative method of making dentures.

- It is suggested that a replacement complete denture technique may achieve the aim of enabling graduates to treat routine cases or diagnose, treatment plan and refer to a clinical dental technician.

\title{
The future of teaching of complete denture construction to undergraduates in the UK: is a replacement denture technique the answer?
}

\author{
R. K. F Clark, ${ }^{1}$ D. R. Radford ${ }^{2}$ and M. R. Fenlon ${ }^{3}$
}

Due to changes in the amount of curriculum time available for teaching complete denture construction to undergraduate students, course content requires reconsideration and possible modification. The idea that a replica complete denture technique may offer some advantages is explored. A review of the relevant literature fails to support many of the claimed benefits of this technique such as relative ease of adaptation by the elderly to new dentures. This article suggests that the replica denture technique should be considered as no more than an alternative method of making dentures. The relative demerits of the technique are discussed. A modification of the replica block technique to include important aspects of conventional complete denture courses is described. It is suggested that, because less clinical time is required, it may be a suitable way of introducing students to complete denture construction and educating them to a level which would encourage some to take further postgraduate study and would allow all graduates to treat routine cases or diagnose, treatment plan and refer to clinical dental technicians.

\section{INTRODUCTION}

In a previous article, Clark ${ }^{1}$ argued for a debate on teaching of complete denture construction to undergraduates. This article is intended to further that debate. Clark ${ }^{1}$ based his argument on the suggestion that edentulous patients could be divided into two groups: those who could manage dentures and those who had difficulties with them. He suggested that the undergraduate curriculum should aim to produce graduates able to treat the first category. Then, in the future, if demand for complete dentures decreases and clinical dental technicians are managing the routine patients, the teaching of complete denture construction

1*Part-time Senior Lecturer/Hon. Consultant, part-time specialist practice 2,3Senior Lecturer/Hon. Consultant, Department of Prosthodontics, GKT Dental Institute, Floor 20 Guy's Tower, Guy's Hospital, London SE1 9RT

"Correspondence to: Robert Clark

Email:rkfc@talk21.com

\section{Refereed Paper}

doi:10.1038/sj.bdj.4811229

Received 13.12.02; Accepted 29.05.03

$\odot$ British Dental Journal 2004; 196: 571-575 will gradually become a postgraduate subject, as orthodontics is now. It will then be necessary to ensure that an interesting undergraduate course is designed so that students might be sufficiently enthused to want to study the subject at the postgraduate level. At first glance, a replacement denture technique seems to offer some advantages in this context. It may be suitable for the target group of patients and has the potential to use less clinical time and so might be suitable for curricula with restricted time allocation for complete denture teaching.

The purpose of this article is to examine this proposition further. But first, the terminology: the literature is replete with different terms with the same or similar meanings such as 'copy denture', 'duplicate denture', 'replica denture' and 'replacement denture' We shall use the term 'replacement denture' to mean the finished denture and 'replacement denture technique' to describe the method. 'Replica' will be used to describe the putative denture at intermediate stages in construction.

\section{REVIEW OF THE LITERATURE}

The replacement denture story begins in the nineteen sixties with the concrescence of three trains of thought. There was the desire to provide edentulous patients with a spare set of dentures identical to the set they were wearing. ${ }^{2,3,4}$ This is an understandable idea which experience has shown seldom works well in practice; however, the techniques suggested may have sowed the seeds of some of the ideas that were developed. There was also the idea that as patients get older they have more difficulty adjusting to new dentures and so copying the old ones would be a sensible approach. ${ }^{5,6}$ Simultaneously, there seemed to be a desire to find a way of making dentures more quickly and by inference more cheaply. $^{7}$

Chick $^{5}$ and Liddelow ${ }^{6}$ were amongst the first to suggest that elderly patients found difficulty becoming accustomed to new dentures that were different to their old ones and they suggested techniques for making dentures similar to the originals. Cost advantages have been advanced by 


\section{EDUCATION}

Scher $^{7}$ but Chamberlain and Basker, ${ }^{8}$ Basker and Chamberlain ${ }^{9}$ pointed out that there was no saving on laboratory or materials costs even if there were savings on clinical time. Kippax et al. ${ }^{10}$ reported difficulties obtaining adequate technical work using a replacement denture technique with significant errors being introduced into the finished denture. The majority of the laboratories surveyed did not fulfil the prescription, although the experimental design precluded normal communication between clinician and technician and this may have prejudiced a more favourable outcome.

\section{Adaptation to dentures by the elderly}

There is little evidence that patients can adapt to copy dentures any more satisfactorily than with correctly constructed conventional dentures. Despite numerous authors citing the rationale for copy dentures being that elderly people have difficulty adapting to new dentures, this appears to be based only on clinical observation. ${ }^{5,11,12}$ Brill et al. ${ }^{11}$ attempted to justify this clinical observation with a discussion of the well-researched evidence that learned reflexes are less easily adopted with age.

Several authors have tried to use stereognosis as an indication of patients' ability to adapt to new dentures, but the results have been inconclusive. Landt and Fransson ${ }^{13}$ demonstrated a decrease in tongue motor skills in a group of elderly subjects compared with a younger group and Koshino et $a{ }^{14}$ observed a decrease in tongue motor skills and masticatory performance, but Muller et al..$^{15}$ were unable to correlate high oral stereognosis scores with adaptation problems, stating that good retention was the best facilitator of adaptation and Slagter et al. ${ }^{16}$ and Koshino et al. ${ }^{17}$ related the ability to adapt to the flatness of the lower ridge. Mantecchini et al. ${ }^{18}$ found that the elderly had worse stereognosis scores than the young, but they found no relationship with length of time the patients had been edentulous. Muller et al. ${ }^{19}$ assessed oral and manual motor ability together with denture adaptation with a questionnaire. They found manual motor ability more closely correlated with age than oral motor ability or denture adaptation and van Akin et al. ${ }^{20}$ could not correlate oral stereognosis with denture adaptation.

Calver and Watt ${ }^{21}$ demonstrated using cinefluorogaphy that the tongue played an important role in the control and retention of an upper complete denture during mastication. In the discussion of their work they attempt to correlate their findings with those of Berry and Mahood ${ }^{22}$ who showed that patients reporting problems with complete dentures had significantly higher oral awareness scores than a cohort of 'successful' denture wearers. The high degree of awareness they postulated may be of significance in patients experiencing what they perceive as looseness and difficulty with wearing complete dentures.

There is controversy as to what factors, if any at all, can predict a successful outcome with replacement dentures. ${ }^{23}$ Certain authors $^{24,25}$ thought that acceptance or rejection of dentures has a low correlation with the clinical quality of those dentures. However, Fenlon et al. ${ }^{26}$ in the largest prospective study on the quality of complete dentures, examined the majority of variables that previous workers have suggested might be of significance. This included the anatomy of the edentulous mouth, the quality of the existing dentures and the new replacement dentures as well as personality factors demonstrated by the Eynenck Short Scale Personality Questionnaire. They showed a significant relationship only between quality of complete dentures (retention, stability, correct retruded jaw relationship, adequate freeway space) and patients' use of complete dentures and between the quality of residual edentulous ridges and patients' use of complete dentures.

Lloyd $^{27}$ in his review of complete denture therapy for the geriatric patient reviewed the literature with regard to oral sterognostic ability, parotid gland function, tooth wear and colour and swallowing reflex time. He demonstrated the fundamental axiom is that as patients age, they become less like one another. ${ }^{28}$ He further commented that negative stereotypes about geriatric complete denture patients include the following: the elderly place very low priority on dental care; are more irritable and demanding than young patients; exaggerate troubles and complaints: denture tolerance is reduced markedly; ability to adjust to new dentures is diminished; the adjustment period is very slow; they have more difficulty adapting to dentures; and have low tolerance to new dentures. When these subjective statements are repeated often enough and without a counter viewpoint expressed for balance, these notions become 'fact. ${ }^{27}$

\section{Studies comparing outcomes of conventional and copy techniques}

Davis and Watson ${ }^{29}$ retrospectively examined the clinical notes of 100 patients treated in an undergraduate clinic, 50 received copy dentures and 50 received complete dentures constructed using conventional techniques. The patients were not randomly allocated and they state that it was difficult to identify the reasons for the supervising clinician advocating one method over the other. However, they did acknowledge that that decision would have been influenced by the clinician feeling that the patient might adapt better to a copy of a reasonably clinically correct denture. Even despite this considerable bias, review visits - perhaps indicating minor denture faults and adaptation difficulties of the patients were similar in number in both groups.

Furthermore, there is a contradiction in the notion put forward by some authors ${ }^{12,30}$ that the replacement technique retains the advantage of producing a denture similar to the old one even if major changes in base extension, tooth position and jaw relationship are incorporated into the new one. Whereas the clinically correct denture that has not deteriorated badly through a lengthy period of wear can be copied with little modification and so it would seem that the patient will adapt well, but again that patient would probably adapt well to conventionally constructed dentures correctly made. However, the reverse is a considerable problem. A set of complete dentures that has poor base extension and errors in both the vertical dimension and retruded position due to excess wear on the occlusal surfaces of the acrylic teeth will need considerable modification to correct these errors - so can they still be considered to be replicas of the originals? Will the patient be able to adapt to them any more easily? There is no evidence to support this view.

\section{Replacement denture techniques}

Chick $^{5}$ developed a technique, which allowed the new dentures to have the same arch form as the old dentures but did not follow exactly the shape of the polished surfaces. He made conventional impressions of the denture-bearing tissues and impressions of the polished surface and teeth of the old dentures. The conventional impressions were articulated using wax occlusion rims. The casts of the old dentures were articulated so that the lower teeth of the new denture could be set up against the cast of the old upper denture. The new upper denture was set up against the new lower and the dentures were processed conventionally. Liddelow 6 developed a similar technique except that he set the upper teeth first and then set the lower teeth to the uppers, which is the traditional order in which to set up denture teeth. Marcroft ${ }^{2}$ used hydrocolloid moulds made of new dentures to make identical spare sets for his patients. Chamberlain and Basker $^{8}$ developed this idea to construct the new dentures from old ones. They used silicone moulds of the old dentures into which either new or custom made teeth were placed prior to wax being flowed into the mould to form the pattern for the denture. 
Later, Wagner ${ }^{31}$ initiated the idea which has become the starting point of all replacement denture techniques ever since. He suspended the old dentures in a bowl and used hydrocolloid impression material (he recommended both reversible and irreversible) to make a mould into which self curing acrylic resin was poured to make a replica of the original denture. He then used these to record his final impressions. Stafford and Huggett ${ }^{32}$ took this technique a stage further. They copied the original dentures but used silicone instead of hydrocolloid. At the next appointment they recorded the jaw relationship of the old dentures and made their impressions in the replicas. After the models were cast they were articulated using the jaw relationship from the old dentures. The teeth were then set up. They do not report how often the jaw relationship of the new dentures was incorrect, but as the position of the replica dentures would have altered once the impression material had been placed in them, occlusal errors in the retruded jaw position would surely be expected.

From this point onwards the literature follows two different paths. There are those that follow more or less the same flawed technique (see below) but vary the materials used for the mould or the replica ${ }^{33,34,35}$ and there are those which develop the technique and improve it. ${ }^{12,36,37}$

In 1978 Duthie et al. ${ }^{36}$ suggested a modified technique which was to become known as the 'replica block technique'. At the first appointment, moulds were made of the dentures using silicone putty and a jaw relationship record made using the old dentures. On the part of the silicone mould which recorded the fitting surface of the denture, a shellac base plate was laid down. The mould was then closed and wax poured in to complete the copy of the old denture. These wax and shellac replicas were then articulated using the jaw relationship record of the old dentures. The teeth were set up one by one in the place of their predecessors. At the next clinical appointment the replicas were tried in the patient's mouth. At this appointment wash impressions were made. Models were poured into the impressions and were flasked without removing the impressions from the models. The shellac, impression material and wax were all removed from the flask at the boil out stage. The dentures were then packed and finished conventionally. Again no mention is made of the fact that the impressions must alter the position of the denture bases and affect the occlusion (see below).

Duthie and Yemm ${ }^{37}$ took the technique forward another step by making the occlusal records on the replicas after the impressions had been made. The replica block technique reached its zenith with Yemm ${ }^{12}$ who acknowledged the developments made in the technique and use of modern materials by the clinicians and technicians at Dundee Dental School. The technique had progressed to acceptance that the jaw relationship record needs to be taken after the impressions have been made and attention needs to be paid to ensuring that the layer of silicone impression material is as thin as possible so as to minimise movement of the replica. Allowance is also made for a facebow record if so desired.

\section{CRITICISMS OF REPLACEMENT DENTURE TECHNIQUES}

Theoretical errors and the introduction of errors

Surprisingly, none of the published papers on replacement denture techniques analyse the theoretical errors inherent in the technique that might occur in replicating old dentures, nor do they stress the importance of correct diagnosis if errors in the old dentures are not to be carried forward to the new ones. These are important considerations clinically and in the teaching situation. Yemm ${ }^{12}$ is the only author who developed his technique over a period of time. The principal problem relates to the relationship between the impressions and the jaw relationship record. Unless the amount and distribution of the impression material used matches exactly the change in shape of the ridge since the dentures were originally fitted, the dentures will be moved in relation to the ridges. This will cause a change in the vertical dimension of occlusion, the intercuspal position will no longer be coincident with retruded relationship of the mandible and lateral occlusions will be affected. There will be a change in the height and orientation of the occlusal plane and the centre line may be changed. The tooth positions will change albeit slightly.

It follows therefore that jaw relationship records must be made after the impressions have been made. As the impressions will have altered the relationship of the dentures to each other, the new jaw relationship record must be taken at an increased vertical dimension of occlusion. Changes to the vertical dimension of occlusion must then be made on the articulator, which would require that the casts be mounted in the articulator at the correct relationship to the hinge axis, using a facebow record. Alternatively, the cusps of the lower teeth must be removed so that the inter-occlusal record, can be made at the correct occlusal vertical dimension.

In addition none of the published techniques mention the need to be able to return the processed dentures to the articu- lator to correct processing errors, nor do they mention the need for a check record and remount procedure.

Failure to understand the laboratory requirements may lead to serious practical difficulties. Kippax et al. ${ }^{10}$ set out to study how well commercial laboratories could follow a prescription and construction of copy dentures following the replica block technique advocated by Yemm. ${ }^{12}$ Although the simulated nature of the protocol lead to difficulties, including where initial laboratory errors were not corrected by the dentist as would occur in practice, they concluded overall that none of the 12 final copy dentures, including one constructed in a University Laboratory, were considered an accurate copy of the original. Seven of the dentures were considered to be unlikely to be successful clinically.

\section{DISCUSSION}

No evidence that replacement denture techniques have any advantages over conventional techniques has been found in the literature. This technique should therefore be looked upon as no more than another way of making dentures. In the context of the debate about undergraduate teaching and the complete denture service provided by dental practitioners, particularly vocational dental practitioners (VDP), a replacement denture technique may offer some advantages, particularly if the shortcomings described above can be overcome. Clinical time may be less. In the undergraduate course this may allow the student to obtain experience of managing patients successfully and at the same time learn some of the important principles of complete denture prosthodontics such as those relating to diagnosis and principles relating to base extension, jaw relationships, tooth positions, occlusion and appearance. Coupled with a successful outcome, some students might be expected to be sufficiently interested to embark on further study. Furthermore, it should be possible within the imposed time restraints to provide graduates with enough background to manage straightforward cases and diagnose and prescribe to clinical dental technicians when they start as VDPs in practice.

The disadvantages of abandoning the traditional teaching and adopting this approach wholeheartedly, lie not only in the disadvantages of the technique itself but also in the academic balance of the course. Dental students take a degree course, which is more than just training for NHS practice. Abandoning the traditional course runs the risk of also abandoning the rich academic component of complete denture prosthetics. Furthermore, to those of us trained in the traditional techniques, the 


\section{EDUCATION}

shortcomings of most replacement denture methods seem to make it difficult to use to make dentures of the highest standard, because at each stage there are opportunities for errors to be incorporated in addition to those inherent in conventional techniques. It may be that without a thorough grounding these sources of error may not be fully understood or even recognised. It is also the case, that the more errors that there are in the original dentures, then the more likely it is that they will be carried forward to the new dentures. The more the dentures need to be corrected, the more demanding the technique becomes, and the more time is required to complete it successfully. It then becomes doubtful if the technique is capable of producing the highest standard of denture unless the old denture itself is in that category. Taken to its logical conclusion there is a moral argument centred on the desirability of a council of perfection versus what is practicable in any particular practice circumstance.

The origin of replacement denture techniques, in the notion that older patients have more difficulty adapting, needs further examination. This view entered the literature in the nineteen-sixties as an opinion, which was not backed up with any research. It was based on the personal experience of the authors. However, since those times our knowledge of complete denture construction has improved, communications have improved and the interchange of knowledge and experience, across the Atlantic in particular, has changed our perceptions and our experiences are different. Now, although most prosthodontists would agree with the general statement that patients' ability to adapt decreases with physiological age, their experiences are based on a better understanding. Experience shows that although an exact copy of a denture which has been worn for years in spite of a few minor errors would probably be accepted by the patient (the more so if the minor faults have been corrected), a new denture with a different group of faults may not be wearable. However, a new denture of different design, which complied to the accepted parameters for a good denture may well be acceptable. Furthermore, a contradiction seems to exist in that replacement techniques are advocated so that the patient is provided with dentures, which are similar to their old ones. However, if the old dentures have many faults requiring changes in base extension and vertical and horizontal jaw relationships, the new dentures may be so different as to not really be considered copies.

This brings us back to the moral argument. Is a wearable denture good enough or should we be aiming at the best possible denture that may enhance the quality of life of the wearer? And should students be taught to make dentures adequately or as well as possible?

We should be honest enough to declare what the aim is. The replacement denture technique offers one solution to the problem of teaching undergraduates to make complete dentures in a restricted time frame and in a system which provides for in-depth teaching at the postgraduate level, may be the solution which suits this country.

The one proviso is that the teachers must be behind whatever is taught, if successful courses are to be provided. For teachers brought up on the traditional teaching, this is not always an easy transition to make. Nevertheless, the traditional teaching is not without its problems. Often complete denture teaching is placed too early in the course, when the students do not know their way around the mouth well and the stages in denture construction are not easy to conceptualise or perform.

In a previous article, Clark ${ }^{1}$ described innovations introduced in the initial undergraduate course when the new dental school was opened in Hong Kong in 1980. A further innovation was to teach immediate replacement dentures before complete dentures. The reason for this was that the students had already completed their course in removable partial dentures and the stages in immediate replacement denture construction and the clinical skills required, have more in common with removable partial denture technique than with complete denture technique. The advantage of this approach was that the students produced a complete (immediate replacement) denture and could see clearly its relationship with the natural dentition. Having provided the patient with a complete denture by this route, the student had learnt much about complete dentures before being confronted by the void of an edentulous mouth. It is a comparatively small conceptual step to replacing the immediate replacement denture with a new denture made by a replacement denture technique.

\section{OUR PROPOSAL}

We would like to propose the following technique for consideration. It combines the best features of Yemm's ${ }^{12}$ replica block technique with the duplication technique described by Neill and Nairn. ${ }^{38}$ It meets our criticisms of previously described techniques and would introduce students to most of the principles of our traditional technique.

\section{First clinical appointment}

As in conventional techniques, a history is recorded and the current dentures inspect- ed to correlate the patient's concerns with the current dentures, their expectations of treatment and any clinical faults with the current dentures. A diagnosis is established and suitable treatment plan discussed with the patient.

Moulds of the patient's dentures are made using silicone laboratory putty according to the technique of Duthie et $a l .{ }^{37}$ (If the bases are under extended it may be worth extending them at this stage before the silicone moulds are made.)

\section{First laboratory stage}

Temporary bases are laid down on the silicone impression of the fitting surface of the old denture. The moulds are then closed and wax poured into the remaining void to complete the replicas, which will have rigid bases and wax teeth.

\section{Second clinical stage}

In principle the impressions should be made before the jaw relationship record, however in order to reduce handling after the impression has been made it is prudent to prepare the replicas for the jaw relationship registration before the impressions are made. Using the replicas, the occlusal vertical dimension, the position and orientation of the occlusal plane, the centre line and the buco-lingual tooth positions are checked and the wax adjusted as required. The cusps of the posterior teeth of the lower wax denture are removed to enable the jaw relationship to be recorded at the appropriate occlusal vertical dimension. Notches are made to facilitate location of the recording material.

An elastomer wash impression is made in each replica. The wax dentures are reinserted in the patient's mouth and the occlusal vertical dimension, position and orientation of the occlusal plane, the centre line and the bucco-lingual tooth positions are rechecked and adjusted if necessary. The retruded jaw relationship record is made and kept on the lower denture. A facebow record is made.

\section{Second laboratory stage}

The impressions are boxed and cast, taking care not to dislodge the jaw relationship record from the lower, however if the record is detached the locating notches enable it to be replaced. The upper cast is articulated using the facebow record and the lower cast mounted using the jaw relationship record. A split cast mounting technique should be used so that the dentures and their models can be removed for processing and returned to the articulator for correction of the processing errors. The teeth are set up, starting with the upper, removing the wax teeth from the replicas one by one. 


\section{Third clinical stage}

The trial dentures are inserted and the occlusal vertical dimension, the jaw relationship, the position and orientation of the occlusal plane the centre line and bucco-lingual tooth positions are checked. The appearance is discussed with the patient. A protrusive record is made.

\section{Third laboratory stage}

The eccentric occlusions are adjusted to ensure good interdigitation at the working sites, a smooth path of movement between eccentric positions and no non-working site contacts. ${ }^{39}$ The wax-up is completed and the dentures processed. The dentures are removed from the flask, but before they are removed from the models they are put back into the articulator and the processing errors are removed. The dentures can then be removed from the models and polished. Mounting casts are poured $^{40}$ in preparation for the check record at the next clinical appointment. Time can be saved at the next appointment if the upper mounting cast is articulated using the existing records, then only the lower cast will have to be articulated once the check record has been made.

\section{Fourth clinical appointment}

The dentures are checked. A check record and remount procedure ${ }^{41}$ is followed so that occlusal discrepancies can be eliminated and a post dam added if the retention of the upper denture needs to be improved. ${ }^{38}$

\section{Comment}

The procedure outlined above mirrors the principles we have incorporated into our traditional complete denture technique. ${ }^{38}$ Only four clinical appointments are necessary if all goes according to plan. It should also be possible to design educational technical exercises around the technique to enable the students to gain the technical skills that they will need to display at the chairside such as adjusting the wax rims and perhaps moving the anterior teeth to improve the appearance.

\section{CONCLUSION}

As a contribution to a debate on the future of teaching of complete denture construction to undergraduates, a replacement denture technique has been suggested as a means of preserving complete denture teaching in the undergraduate dental curriculum. We are aware that some schools already include similar techniques in their undergraduate teaching. We can see advantages for a strategy shared between the dental schools if complete denture construction is to continue to be included in the undergraduate dental curriculum. We hope that this debate will continue.

1. Clark R K F. The future of teaching of complete denture construction to undergraduates. Br Dent J 2002; 193: 13-14

2. Marcroft KR. Fabrication of identical complete dentures. J Amer Dent Assoc 1962; 64: 477-481.

3. Thomson H. Duplication of complete dentures. Dent Practit 1966; 17: 173-175.

4. Manoli S G, Griffiths TP. Duplicate denture technique. JProsthet Dent 1969; 21: 104-107.

5. Chick A O. The copying of full dentures. Dent Practit 1962; 13: 96-98.

6. Liddelow K P. The prosthetic treatment of the elderly. BrDent J 1964: 117: 307-315.

7. Scher EA. A replacement denture technique. Dent Practit 1964; 14: 464-469.

8. Chamberlain J B, Basker R M. A method of duplicating dentures. Br Dent J 1967: 122:347-349.

9. Basker R M, Chamberlain J B. A method for duplicating dentures. Br Dent J 1971; 131: 549-550.

10. Kippax A, Watson CJ, Basker R M. Pentland J E. How well are complete dentures copied. Br Dent J 1998; 185: 129-133.

11. Brill N, Tryde G, Schubeler S. The role of learning in denture retention. J Prosthet Dent 1960; 10: 468-475.

12. Yemm R. Replacement dentures: no friends like old friends. Int Dent J 1991; 41: 233-239.

13. Landt $H$, Fransson B. Oral ability to recognise forms and oral muscular coordination ability in dentulous young and elderly adults. J Oral Rehabil 1975; 2: 125-138.

14. Koshino H, Hirai T, Ishiijima T, Ikeda Y. Tongue motor skills and masticatory performance in adult dentates, elderly dentates and complete denture wearers. $J$ Prosthet Dent 1997; 77: 147-152.

15. Muller F, Hasse-Sander I, Hapfauf L. Studies on adaptation to complete dentures. Part 1 Oral and manual motor ability. J Oral Rehabil 1995; 22: $501-$ 507.

16. Slagter A P, Olthoff L W, Bosman F, Steen W H. Masticatory ability, denture quality and oral conditions in edentulous subjects. J Prosthet Dent 1992; 68: 299-307.

17. Koshino H, Hirai T, Ishijima T, Ohtomo K. Influence of mandibular residual ridge shape on masticatory efficiency in complete denture wearers. Int J Prosthodont 2002; 15: 295-298.

18. Mantecchini G, Bassi F, Pera P, Preti G. Oral stereognosis in edentulous subjects rehabilitated with complete removable dentures. J Oral Rehabil 1998; 25: 185-189.

19. Muller F, Link I, Fuhr K, Utz K H. Studies on adaptation to complete dentures. Part 11 Oral stereognosis and tactile sensibility. J Oral Rehabil 1995; 22: 759-767.

20. van Akin A A, van Waas M A, Kalk W, van Rossum G M Differences in oral stereognonsis between complete denture wearers. Int Dent J 1991; 4: 75-79.

21. Calver PA J, Watt I. Denture movements and control. BrDent J 1973; 135: 111-116.

22. Berry D C, Mahood M. Oral sterognosis and oral ability in relation to prosthetic treatment. Br Dent J 1966 120: 179-185.

23. Berg E. Acceptance of full dentures. Int Dent J 1993; 43: 299-306.

24. Langer A, Michman J, Seifert I. Factors influencing satisfaction with complete dentures in geriatric patients. J Prosthet Dent 1961: 11: 1019-1031.

25. Smith M. Measurement of personality traits and their relation to patient satisfaction with complete dentures. J Prosthet Dent 1976; 35: 492-503.

26. Fenlon M R, Sherriff M, Walter J D. An investigation of factors influencing patients' use of complete dentures using structural equation modelling techniques. Community Dent Oral Epidemiol 2000; 28: 133-140.

27. Lloyd P M. Complete-denture therapy for the geriatric patient. Dental clinics of North America 1996; 40: 239-254.

28. Maddox G L. Aging differently. Gerontologist 1987; 27: $557-564$

29. Davis D M, Watson R M. A retrospective study comparing duplication and conventionally made complete dentures for a group of elderly people. $\mathrm{Br}$ Dent J 1993; 175: 57-60.

30. Davis D M. Copy denture technique: a critique. Dent Update 1994; 21: 15-20.

31. Wagner A G. Making duplicate dentures for use as fina impression trays. J Prosthet Dent 1970; 24: 111-113.

32. Stafford G D, Huggett R. The use of duplicate dentures in complete denture construction. Dent Practit 1971; 22: 119-121.

33. Heath $J R$, Basker R M. The dimensional variability of duplicate dentures produced by an alginate investment BrDent J 1978: 144: 111-114.

34. Heath J R, Davenport J C. A modification of the copy denture technique. Br Dent J 1987; 153: 300-302.

35. Cooper J S, Watkinson A C. Duplication of full dentures. Br Dent J 1976; 141: 344-348.

36. Duthie N, Lyon F F, Sturrock K C, Yemm R. A copying technique for replacement complete dentures. $\mathrm{Br}$ Dent J 1978; 144: 248-252.

37. Duthie N, Yemm R. An alternative method for recording the occlusion of the edentulous patient during construction of replacement dentures. J Oral Rehabil 1985; 12: 161-171.

38. Neill D J, Nairn R I. Complete denture prosthetics. 3rd ed pp 126-131 Bristol: Wright 1990.

39. Nairn R I. Lateral and protrusive occlusions. J Dent 1973: 1: 181-187.

40. Clark R K F. Complete denture mounting casts with intact anatomical landmarks. J Prosthet Dent 2001; 86: 443 .

41. Preiskel H W. Considerations of the check record in complete denture construction. J Prosthet Dent 1967; 18: 98-102. 